\title{
An intemupted transmission? Processes of CCTV implementation and the impact of human agency.
}

\author{
Pete Fussey1
}

\begin{abstract}
This paper examines the processes that bring about the creation of new public-space CCTV schemes. Through an appraisal of the grounded activities of the practitioners who make decisions over CCTV, the role of agency is identified as a particularly strong, yet relatively neglected, influence on its implementation. Moreover, beyond dichotomised notions of central structures and local agency, an understanding is developed of the complex interaction between the individual actors involved in CCTV dissemination and the political context in which they operate. In doing so, public policy is identified as the vehicle through which camera surveillance systems become installed and disseminated throughout public space. Moreover, these various forces of structure and agency become filtered through identifiable networks of policy-makers, comprising 'responsibilised' actors who oversee the deployment of CCTV. This analysis is used to revisit a range of administrative and theoretical understandings of surveillance, including: citations of CCTV as an evaluated response to crime; the attribution of power- and interest-based agendas to its implementation; and accounts which locate CCTV expansion within various evolving societal processes. Drawing on qualitative fieldwork data gathered during doctoral research, the paper considers the activities of practitioners at a local level and identifies crucial contexts, drivers and negotiations on which expanding surveillance is contingent. Ultimately, it is argued that the process of CCTV installation - from conception to material implementation is disrupted and mediated by a range of micro-level operations, obligations, processes, managerial concerns (particularly conflict resolution and resource issues), structures and agency, and the indirect influence of central government. These not only arbitrate over whether the CCTV becomes installed, but also generate a range of additional uses for the cameras, many of which are performed before they are even switched on. This emphasises the need to consider the processes that enable and constrain the actions of those making decisions over CCTV and demonstrates how no single interest becomes solely participant in the deployment of surveillance. Finally, because of the centrality and contingency of both human agency and the structural contexts in which it operates in determining the installation of CCTV, questions arise concerning the importance of integrative sociological theories in understanding the deployment of surveillance.
\end{abstract}

1 University of East London, mailto:pete.fussey@uel.ac.uk 


\section{Introduction}

Surveillance is by no means a new phenomenon. Historical accounts, for instance, cite embedded surveillance practices operating in the control of the Athenian Agora and the Roman Forum (Sennett, 1990). However, over more recent years, surveillance has become a central feature of contemporary society (Lyon, 2001). What is different about contemporary manifestations of surveillance is its recent growth through technological developments ultimately generating novel means and forms of data extraction and mechanisms for controlling crime and disorder - culminating in new and shifting interactions between surveillance technology and society. However, it has been the explosion of CCTV surveillance cameras onto British streets since the early 1990s that has been perhaps the most politicised, recognisable and commented-upon manifestation of this technological expansion of surveillance. British citizens now experience the most intensive public camera scrutiny in the world (Graham et al., 1996; The Independent, 2004), where Londoners can expect to be filmed by, on average, around 300 cameras a day (Norris and Armstrong, 1999).

Through an empirical examination of the grounded activities of the individuals who oversee the deployment of CCTV, this paper seeks to examine some of the mechanisms and processes that lead to the dissemination of these surveillance strategies across the UK. Before doing so, this paper first offers a brief review of some of the thematic ways in which such technological surveillance has been understood.

\section{Theorising CCTV}

This proliferation of technological surveillance has hardly gone unnoticed and the functionality of CCTV has been understood in a variety of ways; through applied and theoretical standpoints alike. Taking a general view of this literature, Fyfe (2004) notes an increasing tendency for utopian and dystopian discourses to prevail in such debates. Indeed, the utopian label has regularly been applied, often with good reason, to practitioners' and politicians' claims that CCTV could provide the solution to rising rates of criminality during the early to mid-1990s. However, since then, evidence of a more nuanced and realistic understanding of its capabilities is beginning to emerge in administrative circles (inter alia Welsh and Farrington, 2002).

Many critical sociological approaches to surveillance - and CCTV in particular - emphasise the 'dystopian' side of the coin and have drawn heavily on prominent and recurring themes. For instance, Haggerty and Ericson (2000: 605), Hier (2003), Williams and Johnstone (2000) and Lyon (1994) all note the dominance of Orwellian and Foucauldian paradigms within the field of surveillance studies. Others, such as Newburn and Hayman (2001), stress a tendency to describe CCTV in terms of a 'maximum surveillance society' (see Norris and Armstrong, 1999) or 'Big Brother' (Davies, 1996a). Recently, commentators have also observed the prominence (Webster, 2004) or over-representation (Coleman, 2004) of work seeking to understand CCTV through Foucault's (Benthamite) metaphor of the Panopticon as a blueprint for the network of unrelenting observation underpinning the wider dispersal of societal control. 
Similarly, Fussey (2004) notes the prominence of neo-Marxist and Foucauldian theoretical groundings in many accounts of surveillance, whilst Bogard (1996) adds Weber to this binary.

However, critical examinations of surveillance have proliferated in recent years and generated a range of interesting and important theoretical approaches. One particularly influential and growing body of work, for example, implicates CCTV in the sorting of gendered, racialised or socio-economic 'difference' in late-modern urban spaces (inter alia Seabrook and Wattis, 2001; Norris and Armstrong, 1999; Davis, 1998 respectively). Paralleling urban geographical themes of divisive space (see Soja, 1989), this latter theme of socio-economic difference has been critically examined as a process by which economically powerful groups in society gain power through the private management of public space, a transition characterised by some as a subtle form of privatisation of public space (Graham et al., 1996). This development has been similarly described as fostering the emergence of 'neoliberal spaces' (Brenner and Theodore, 2002), whereby an individual's capacity for consumption influences access to zones of formerly public space. For many commentators, CCTV has been a complicit tool in ordering and policing this division between potential consumers and non-consumers in late-modern urban spaces (inter alia Beck and Willis, 1995; Bannister et al., 1998; Coleman and Sim, 1998, 2000; Norris and Armstrong, 1999; Williams et al., 2000; Toon, 2000; McCahill, 2002; Fyfe, 2004) and its ubiquity in commercial centres is perhaps testament to this. Such developments have also connected with varying reflections on late-modern (re)configurations of governance (inter alia Coleman, 2004; McCahill, 2002; Norris and McCahill, 2006).

Although the above themes represent a sizable portion of 'surveillance theory', other theoretical positions have sought to develop and build on Foucault's work. Here, the work of Giles Deleuze (1995) has gained particular ascendancy, chiefly in reference to his conceptualisation of 'societies of control'; a condition that supersedes Foucault's disciplinary society. Continuing Foucault's theme of the ubiquity of power, Deleuze characterises a paradoxical co-existence of greater control alongside its reduced physical tangibility. Such control is thus exercised though illimitable and unending 'modulation' as opposed to Foucauldian depictions of 'moulding' into a specific 'normalised' form (Deleuze, 1995: 179). In the most explicit adaptation of Deleuzian 'control' into explanations of surveillance, Haggerty and Ericson (2000) note the convergence of control and surveillance systems, specifically through the development of 'surveillant assemblages'. Briefly, these assemblages capture various information flows and re-assemble them into observable phenomena. In conceptualising the lack of institutional boundaries of such assemblages, Haggerty and Ericson forward the concept of 'rhizomatic surveillance' which incorporates a central feature of expansion. This expansion refers to the exponential growth of surveillance which both subsumes new technology and systems whilst simultaneously drawing existing surveillant forms into assemblages.

Whilst these theoretical arguments clearly have a great deal to offer, much of the emphasis is orientated around the functionality of surveillance once installed and operational. This paper, however, examines what happens in order for surveillance provisions to become deployed in the first instance, thus examining some of the complex processes surrounding and leading to implementation of CCTV. Moreover, many (though clearly not all) of the above descriptions of the operation of CCTV harbour an implicit suggestion that surveillance is installed - or 
expands - to reflect particular agendas (for example malign corporate intent) or evolving processes (such as wider shifts towards societies of control). This paper conceptualises this process as one of a 'transmission' from concept to manifest CCTV implementation.

Moreover, the transmission of CCTV from concept to practice remains an underdeveloped theme, as investigations into the implementation of public surveillance cameras constitute an under-populated region in the burgeoning field surveillance studies. One notable exception, however, is Graham's (1998) examination of the growth of CCTV surveillance to become what he describes as a 'fifth utility' in Britain's urban environments alongside electricity, gas, water and telecommunications. Here, Graham argues that CCTV implementation is propelled by the combination of 'supply push' and 'demand pull' factors. Regarding the former, powerful local coalitions - incorporating elements from the media, the police, local authorities, commercial interests, insurance companies and, perhaps most significantly, the surveillance 'industrial complex' (including CCTV manufacturers, ICT companies, private security firms, 'consultants' and other service providers) - generate an irresistible drive for the implementation of public space surveillance cameras. For Graham, this intersects with a 'demand pull' from (methodologically flawed) polls of a public seemingly unconcerned over issues of privacy and civil liberties (and, one might add, the many limitations of CCTV) given the prospect of increased 'security'. Once installed, CCTV then follows an 'expansionary logic' where it makes sense to incorporate unobserved areas into surveillance networks.

Such observations raise many interesting questions regarding how such influences spur the installation of CCTV. For example, how do particular supply 'interests' gain primacy? Given the diverse occupational cultures behind the development of crime control strategies (inter alia, Sampson et al., 1988; Crawford, 1998), what happens if conflicts and disagreements arise within such coalitions? How is discord negotiated? Likewise, does public demand simply become transmitted into manifest strategies? If so, whose demands are articulated and which mechanisms allow them to become galvanised?

This paper argues that surveillance neither operates nor is it implemented within a vacuum. Instead, myriad direct and indirect influences can be identified as exerting themselves on - and propelling - public CCTV implementation from its conception as a policy decision, to its manifestation on Britain's streets. Furthermore, it argues that 'messy' arrangements and nonuniform assertions of human agency impacting on the creation of CCTV strategies mean that there is still much to learn about this process of 'transmission' as it relates to CCTV. Such recognition of agency, it is argued, may also serve to supplement and facilitate reflection on many of the existing accounts of surveillance discussed above.

To understand such processes, this paper acknowledges the recent and growing body of literature identifying the need to understand technology and surveillance through recognition of its wider political and social contexts alongside what happens locally (inter alia Graham and Marvin, 1996; Lyon, 2001; McCahill, 2002). This need is responded to here through an examination of the micro-level processes and, crucially, applications of agency which shape the implementation of public-space CCTV systems. However, this attention to local action does not 
constitute an exclusive emphasis. Instead, the manner in which external forces interact with local activity is also recognised as an important site of analysis.

To develop a conceptual framework allowing for a nuanced understanding of the complex interplay between individual agency and the social environment in which surveillance strategies are formulated, Lyon's (2002) argument concerning the profound interconnectivity between the study of surveillance and of policy analysis is acknowledged. Taking Lyon's comment as a starting point, public policy is identified as the vehicle through which open street camera surveillance systems become installed and disseminated throughout society. Moreover, these various forces of structure and agency become filtered through identifiable networks of policymakers, comprising responsibilised actors (Garland, 1996) who oversee the deployment of CCTV. ${ }^{1}$

Specifically, these identifiable networks are coalesced into community safety partnerships which have been formalised, and in many cases established, since the 1998 Crime and Disorder Act (CDA). Under this legislation, these partnerships are given the responsibility to generate crime control strategies in their particular locations in the UK. Hence, these are argued to be the location where crucial decisions are made regarding the implementation and dissemination of public CCTV surveillance and its application in particular roles. Political pressures and public demands to install CCTV, the assertion of practitioner knowledge concerning its effectiveness and the generation of funding for their installation are all filtered through such partnerships. These forums therefore constitute the site where the transmission of CCTV policy is interrupted, shaped and modulated.

The following findings are presented in a form which acknowledges Graham's (1998: 90) notion of 'supply-push' and 'demand-pull' pressures upon CCTV. Here, this typology is used as a lens by which to view a broad range of differing influences empirically identified as asserting themselves upon the processes that govern CCTV installation. Moreover, because of the unpredictable impact of human agency on such processes, the analysis then examines the role of partnerships as conduits in which competing pressures and beliefs concerning CCTV and its capabilities are contested and negotiated. Before discussing these findings, this paper will now outline the methodological apparatus employed for the collection of data.

\footnotetext{
1 This process of 'responsibilisation' relates to Garland's (1996) observation that state authority for protecting the public and, hence, developing and implemented anti-crime strategies was becoming devolved onto (responsibilised) local-level actors. The extent of this deputation constitutes a much-debated issue amongst criminologists (see inter alia Garland, 2001 and, with specific reference to CCTV, inter alia Coleman, 2004; Fussey, 2004).
} 


\section{Methodology}

A combination of qualitative methodologies were employed to examine the perceptions and practices of responsibilised agents involved in generating crime control strategies, including CCTV, working within post-CDA crime and disorder partnerships in two different English urban areas. During the fieldwork, CCTV systems were at various stages of development across both partnerships - ranging from proposals for new systems to the upgrading of existing networks. As such, the intention of this paper is to ascertain the myriad influences impacting upon such CCTV policy processes.

\section{Site Selection}

These sites were selected according to a number of criteria relating to variations in the composition of the different partnerships and urban contexts they operate within. Here, two case studies were chosen: Industrial Town and Metropolitan City.

By UK standards, Metropolitan City is a reasonably large city with a population in excess of 300,000 people. Once thriving and famed for its manufacturing industries - and also once host to one of the UK's most important sub-cultural music scenes - Metropolitan City experienced significant socio-economic decline following a period of de-industrialisation during the 1980s and 1990s; a process that has left some areas of the city amongst the most deprived in he country. Such areas were also the sites of major public disorder during the 1980s. Perhaps intrinsically linked to such issues, Metropolitan City has been at the forefront of many crime prevention initiatives, including CCTV. CCTV was first installed here during 1988, when nine cameras were set up to monitor covered pedestrian walkways in the city centre. The CCTV network was then substantially upgraded in 1991 by another 49 (city-centre) cameras. Over a decade later, during the time of research, this figure had doubled, with more than 120 cameras surveying the city. During this period of fieldwork, the systems were being upgraded once more and also rolled-out into residential areas of the city.

By contrast, Industrial Town is a much smaller location with a population of around 100, 000 residents. Once focused around local engineering and manufacturing, Industrial Town is now experiencing expansion in the service and leisure industries. The crime control partnership was only recently developed in 1999, following statutory obligations imposed by the CDA. This marks an interesting distinction between the sites and provides potentially fruitful ground for the analysis of the processes, initiatives and the influence of Home Office directives on local partnerships. $^{2}$ CCTV was first introduced into Industrial Town during 1995. At the time of research, the network incorporated 64 Pan, Tilt and Zoom (PTZ) cameras and had recently introduced three mobile camera units for flexible deployment; roughly half the public-space cameras of Metropolitan City. Again, cameras were beginning to be disseminated into the town's residential spaces.

\footnotetext{
2 The UK Home Office is a major government department, which, amongst other functions, is charged with generating and delivering crime control policy (although also see endnote 1). As of May 2007, the department will become divided whereby its criminal justice functions will be relocated to a new 'Ministry of Justice'.
} 


\section{Sampling and Data Collection Tools}

In doing so, a purposive (non-probability) sampling approach was employed to select the potential participants of research enquiry based on a particular characteristic (inter alia May, 2001), in this case, membership of one of the crime control partnerships. Thirty-nine semistructured interviews ${ }^{3}$ were initially conducted, which combined with follow-up interviews and discussions culminated in around 60 hours of research data. These were supplemented with more informal face-to-face, telephone and email conversations (used to clarify and test the validity of emerging themes) and also complemented with an analysis of documents depicting policy decisions, published reports, community consultation exercises, minuted meetings and CCTV funding applications. Key research methods are now discussed in greater detail.

The interviews covered a range of different agencies representing diverse interests, for example, from the police to representatives from the voluntary and private sectors. Because hierarchical structures and lead agencies affecting CCTV policy processes were not immediately obvious prior to engagement with the research field, snowball sampling techniques were adopted. This helped to identify key players in the development of CCTV strategies and subsequently allowed their contributions to be accented according. Generally speaking, the central actors and lead agencies were revealed to be local authorities and the police as they usually (although not exclusively) presided over the generation of crime control responses, orchestrated public consultation exercises, brokered the 'knowledge' for possible strategies and organised their funding. Of those participants quoted in the findings below, each either exerted a significant influence on the development of actual and proposed CCTV schemes or was well-placed to describe particular processes. Their particular role and influence is stated as their contributions are introduced.

All interviews (with one exception) were recorded and then fully transcribed. This was done to facilitate a more thorough examination of statements, reduce bias and help avoid the 'intuitive gloss' (Heritage, 1984: 238) researchers may add to respondents' actions. The transcribed data was then analysed inductively to identify significant and emerging themes and then re-examined in a more systematic manner to assess whether others reflected such issues. For example, some practitioners' descriptions of non-technological surveillance (see below) became a key theme once their interconnection to CCTV was flagged in later interviews. Once its significance was understood, the data could then be re-visited for evidence of this previously overlooked theme amongst the testimony of other participants. The quotations presented below are indicative of these themes.

Aside from the informal interactions with participants mentioned above, the research interviews were also supplemented with documentary sources. These took two forms: documents obtained from central government and those from local sources pertaining to the work of local partnerships. The former were analysed to establish the government's stance in relation to

\footnotetext{
${ }^{3}$ Because partnerships are shaped by local agency and negotiated realities, data was needed to reflect how practitioners saw their work, thus informing the decision to employ qualitative semi-structured interviews (SSIs). Moreover, SSIs were deemed appropriate as they would allow latitude for probing and theme development during the interview setting whilst retaining a degree of comparability across the data.
} 
CCTV and how these formed recommendations for local networks. Additionally, central government requirements for the formations of the local structures where decisions over CCTV were taken were also examined. Typical government documents used included the Home Office 'toolkits' for action on given problems of crime, particularly in relation to where the government perceived that CCTV was best deployed; Home Office advice on bidding for CCTV funding; and also guidelines, obligations and advice regarding the formation and operation of the partnerships themselves, as forums for where decisions for the deployment of strategies such as CCTV are taken.

Local documentation outlined partnerships' agreed aims, objectives and strategic decisions, which illustrate trends in policy-making, broad approaches to crime control and their underpinning theoretical basis. Typical sources of information for this type of data were the annual action plans produced by each partnership. Local documentation was also employed to ascertain how local practitioners interpreted and responded to Home Office requirements, an issue that was particularly clear in the documents submitted to the government for CCTV funding. Another important local documentary source were the crime and disorder audits carried out every three years (a mandatory obligation under the CDA). These highlight what problems are perceived in the particular locality, key issues on which strategies are based whilst also indicating the orientation of both partnerships. Finally, minutes of partnership meetings were drawn upon to corroborate the key actors and agencies driving CCTV policy al ong

\section{Introducing the findings}

Many of the theoretical positions discussed above are contrasted by official discourses which stress a narrow and supposedly objective rational (and hence benign) approach towards CCTV implementation. Here, CCTV is said to be installed in response to an application of the most effective strategy based on evaluated evidence of 'what works' in responding to an identified problem of crime and/or disorder; an approach also articulated as a scanning/analysis/response/assessment' model (SARA). Notwithstanding the extreme difficulties in quantifying such a breadth of social life into measurable criteria whilst simultaneously gathering sufficient methodologically robust data to adequately know 'what works' in given contexts, recourse to evaluative studies was conspicuously absent in both partnerships. Moreover, coordinators of both partnerships stressed a more ad-hoc and flexible set of arrangements governing crime control policy-making. As such, this paper acknowledges criticisms regarding the over-determinism of administrative approaches (McCahill and Norris, 2002) and argues that such claims of CCTV as a rationally-contrived response to evaluated induces of crime ignore the more uneven and extraneous influences affecting practitioners working in grounded policy contexts.

Moreover, such influences can be broadly characterised within the sociological heuristic of agency and structure. In terms of agency, complicit practitioners receive and mediate the various 
demand and supply forces driving CCTV and imprint their own interpretations during the transmission of CCTV policy from idea to manifest strategy. This agency also acts in relation to influential structural factors including: the tension between central and local government, the formulation and stratification of local structures, post-CDA policy-making arrangements stressing consultation (which raise the profile of low-level disorder, particularly in residential areas), legitimating obligations remedied through the tangible symbolism of CCTV and managerial considerations, comprising time and money resource issues and the need to secure consensus within a diverse partnership.

To examine such impositions of agency and structure in more detail, this paper now presents the empirical findings in relation to the supply-side and demand-driven drivers for CCTV and, finally, the way in which such forces become negotiated within partnership settings.

\section{Supplying surveillance}

Contrary to assertions made in other work in this area (inter alia; Graham, 1998), within these partnerships, no evidence was found of pressure from CCTV manufacturers to install their product in the public sphere. This is caused by a number of factors largely concerning the processes occurring before such decisions can be made. For example, as following discussions show, public and political pressure for CCTV is significant enough to strongly influence the decision to pursue the implementation of public surveillance cameras. For such reasons, practitioners understandably see CCTV as an attractive tool. ${ }^{4}$ However, one overwhelmingly significant factor facilitating the supply of CCTV consistently pointed to by practitioners was the existence of available Home Office funding earmarked for CCTV implementation.

Because securing the resources for the installation of CCTV is a key factor determining whether the systems are actually implemented, it is necessary to briefly consider how this occurs and what its effects are. In doing so, an argument is forwarded that the way in which cash resources are obtained and the conditions imposed on the dissemination of funds have sizable implications for how CCTV policy is formulated and subsequently implemented. Such issues also reflect on a number of theoretical approaches, particularly concerning governance and CCTV, although these have been examined in more detail elsewhere (inter alia Fussey, 2004).

The man source of funding for CCTV schemes is from the annual Home Office CCTV Initiative. As an indication of its size, the first Home Office CCTV Initiative - replacing the earlier CCTV Challenge Scheme in 1999 as part of the government's Crime Reduction Programme - made $£ 153$ million available from 1999 to March, 2002 (Home Office, 2001). In practice, the capital (installation and initial set-up) costs for all new public CCTV schemes in both partnerships was supplied by the Home Office, whereas day-to-day management costs are met locally. The other potentially significant sources of CCTV funding are the Single Regeneration Budget (SRB) and the local council, although in both partnerships these alternative

\footnotetext{
${ }^{4}$ Additionally, no evidence was found of mechanisms for private companies to meaningfully lobby practitioners.
} 
sources were barely significant by comparison. Moreover, the reliance on Home Office funding is so great that if a bid collapses, CCTV systems are not implemented. This has occurred on a number of occasions in both partnerships (Interviews 1, 15 and 35). ${ }^{5}$

However, gaining cash resources from the Home Office is a complex affair involving strict criteria and adherence to specific processes. In particular, the central government can be seen to use its control of funding to both influence local agendas and to affect which strategies are applied. Yet it is important to note that this does not necessarily mean a simple transmission of state values into the local sphere; practitioner agency retains a crucial influence on the dissemination of strategies such as CCTV (see below). As many studies have shown, local managers often add their own interpretations to those policies made at the top (inter alia Crowther, 2000). Nevertheless, the influence of government funding criteria on local practices is also an implicit theme in the following discussions.

\section{The supply of surveillance in different spaces}

Examination of the drivers behind CCTV implementation also identifies important differences between different types of urban spaces, particularly between residential and central commercial areas. Whilst urban centres were largely saturated with CCTV cameras by the mid 1990s (Graham et al., 1996), their expansion into residential contexts has been slower. However, the turn of the millennium marked a change in policy whereby areas of greater residential density became the new sites of CCTV expansion. Of the funds made available by the government at this time, around half are allocated for this purpose (Home Office, 2000a, 2000b). Indeed, both research sites had also begun to disseminate CCTV into residential areas since the early years of this decade. Because of substantial differences between the implementation of CCTV depending on its central or residential location, this expansion is significant at both practical and theoretical levels. This is because CCTV strategies are fostered by differing drivers, aims and applications dependent on location. For example, CCTV implementation in residential areas appears to be more driven by public pressure and opinion (often in response to experienced 'environmental incivilities'), rather than solely the interests of business. This is exacerbated through increased population density in residential spaces and post-CDA requirements for public consultations as a basis for strategies. Whereas interest-based and political-economic accounts of CCTV expansion have been quick to point to the role of corporate interests in the lobbying for CCTV, this is clearly less pronounced in urban residential areas. Ultimately, this signifies the importance of recognising specificity and sensitivity to its situational contexts when conceptualising CCTV installation processes. This also represents the need to draw boundaries around the applicability of such corporate interest-based explanations of CCTV within wider urban geographies.

\footnotetext{
5 Interview 1 was conducted with the overall co-ordinator for crime control strategies within the Industrial Town partnership. The participant for Interview 15 occupied a similar role covering a north-eastern region of Metropolitan City. The head Police representative to the Metropolitan City partnership was questioned in Interview 35.
} 


\section{Human Mediation and the Commitment to Surveillance}

Surveillance cameras are not only supplied into differential spaces, but are also located within varying strategic contexts. One of the significant recent changes in Home Office funding criteria involves the requirement that CCTV must be installed alongside a raft of other preventative measures. During the 1990s, for example, practitioners could submit successful funding bids whereby CCTV was the sole strategy (provided there was public support and available funding to meet maintenance costs). Now, however, there was recognition that bids would only be deemed credible provided CCTV is implemented alongside potentially complementary measures; thus located within a strategic context. This change is significant for a number of reasons. In the first instance, this (state and local) insistence that CCTV must be combined with other strategies represents an acknowledgement that CCTV is no longer the panacea, 'silver bullet' (inter alia Davies, 1996b) or all-encompassing 'technofix' it was perhaps once thought to be; thus indicating a growing awareness of its limitations. ${ }^{6}$ The fact that this position has changed also points to the need to recognise the contingency of CCTV expansion on the prevailing attitudes of the time. Because the attitudes of human actors change, this signifies the need for explanations of CCTV dissemination to recognise the specificity of time as well as place.

Typically, these polystrategic packages combined CCTV with variants on neighbourhood wardens ('CCTV on legs' according to one practitioner), 'shop-watch' and 'pub-watch' schemes involving reporting of suspicious persons to other businesses in an area, radio links, Neighbourhood Watch and enhanced street lighting provisions. All of these centre on aspects of increased visibility, observation or monitoring capabilities. Ultimately, this not only represents confidence in such solutions, but also signifies an orientation of strategy around the goal of increased surveillance provisions whereby CCTV is a major feature.

Hence, whilst a clear commitment towards increasing surveillance is evident in new crimecontrol strategies, CCTV is increasingly complemented by informal, less technological and human forms of observation and integration. Thus, wider commitments to surveillance do not necessarily denote the endorsement of technological forms. This theme also raises two theoretical points. In the first instance, this reflects on Haggerty and Ericson's (2000) depiction of a converging surveillance assemblage where technology is reproduced and increasingly networked with the aim of solving social problems. Whilst they acknowledge the role of human actors in the wider assemblage, they argue that where technology has yet to link surveillance systems together, human contact points are used as a substitute. Within this context, however, a paradoxical process is also in evidence where solely technological solutions are now becoming supplemented by the human agent. This reinstatement of the human agent into informal surveillance networks may also engender a high degree of inefficiency and unpredictability, as McCahill (2002) notes in relation to the 'human web' of CCTV observers.

\footnotetext{
${ }^{6}$ Installing CCTV alongside other measures also makes it more difficult to assert that any reductions in crime are solely attributable to the cameras.
} 
This marriage of CCTV and low-tech human networks of surveillance also suggests that, whilst many practitioners have a degree of faith in the ability of CCTV, they are not entirely (and passively) seduced by discourses of technology. Rather, faith in this particular technology is grounded in complex practical settings and ideological attitudes which help to stimulate its expansion. It is not necessarily because they are technological in themselves that they are supported, but potentially because such strategies incorporate ideas that find harmony with deeper beliefs regarding appropriate responses to crime. For practitioners in this context, CCTV embodies ideas that have attained status in both partnerships, including operational enforcement, and administrative notions of rational choice theory and 'capable guardianship'. Such approaches also meet the defined partnership aims of tackling incivilities and promoting community sentiment. These intersect with contextual circumstances which constrain the opportunities for alternatives whilst generating mechanisms which favour CCTV implementation. Other technologies, such as electronic tagging, by contrast, may not have the same appeal (and hence strength of 'technological discourse') because they have an operational grounding which is at variance with popularity of this type of control.

\section{Latent utility and 'presurveillance'}

The fact that practitioners perceive CCTV as being capable of fulfilling a number of tasks is perhaps unsurprising. Indeed, a cursory glance at Home Office advice on crime control that is disseminated to practitioners in the form of 'toolkits' cites CCTV as a crucial recommended 'evaluated option' to tackle the following disparate range of offences:

- 'vehicle crime'

- 'street crime and robbery'

- 'burglary'

- 'anti-social behaviour'

- 'rural crime'

- 'transport'

- 'race crime and harassment'

- 'communities against drugs'

- 'persistent young offenders'

- 'business and retail crime'

- 'arson'.

(Home Office, 2004)

Leaving aside the significant conjecture in claiming that CCTV has somehow been evaluated as a response to all of these issues with any methodological rigour (see inter alia Pawson and Tilley, 1994; Davies, 1996a; Short and Ditton, 1995; Tilley, 1998; Welsh and Farrington, 2002; NACRO, 2002), not to mention the lack of awareness of any such evaluations amongst respondents, it is clear that CCTV is presented as effective in a wide range of applications. On a more general level, recent contradictory themes in government crime control policy - outlined by Garland (2001) as punitive drives based on cultures of insecurity and also rationalised managerial responses to crime - have been described as neatly serviced by CCTV (Sutton and Wilson, 2004). CCTV has also been identified as occupying a symbolic role where partnerships 
can overcome struggles for legitimacy by demonstrating tangible responses to community fears (Fussey, 2005).

However, the data also revealed an additional theme concerning the pre-active functionality of residential-space CCTV. Here the means of CCTV dissemination are as valuable as its perceived end. Like the legitimating and symbolic roles identified above, in this respect CCTV appears to fulfil a number of important functions before it is even switched on; functions characterised here as 'presurveillance'.

In the main, these preoperational functions of CCTV intersect with notions of community cohesion, transition and environmental improvements - all of which were key concerns for both partnerships. Two examples of how this may occur now follow:

These sentiments were expressed across Metropolitan City where attempts were made to encourage commercial and service infrastructures to operate in particular areas (Interview 25), reduce population transience and help generate stability and cohesion in the community (Interviews 14, 21). Such aims clearly informed one proposed CCTV scheme as part of a regeneration project in one deprived non-central urban area, 'Hall End', whereby CCTV was part of an attempt to encourage local businesses and services into the area. Such preoperational application of CCTV again reflects on political-economic accounts, which have less to say about surveillance camera installations in residential areas. Although political-economic accounts have rightly pointed to the prominence of less than benign neo-liberal models of regeneration that reinforce structural inequalities and 'manage out' the urban poor (inter alia Bannister et al., 1998), this is not always the only effect in residential spaces. The 'Hall End' estate - positioned beyond the suburbs on the edge of Metropolitan City as part of the 'urban leapfrog' from inner-cities during the 1960s - had been all but abandoned of basic amenities such as local shops and laundrettes (along with one-third of properties lying vacant). Hence, the businesses focused upon were local and small-scale, rather than multi-nationals (who had exited the estate years before) concerned with attracting middle-class consumers. Indeed, outsiders rarely ventured on the estate without necessity and the nearest bus route skirted the area. Likewise, anecdotal evidence indicates that taxis also routinely refused to drive into the area. 'It's not the place to go to. It's a place to come from', as the local Community Safety Officer puts it (Interview 25). Hence, rather than solely functioning to persecute particular subpopulations to 'improve' consumer space, CCTV may be applied in an attempt to engender such forms of cohesion and stability. This signifies a potentially paradoxical role of CCTV implementation, which threatens urban diversity through the 'sorting' of social difference yet by forming part of a strategy to counter community transition and disorganisation through retention of community amenities - simultaneously aims to ground disparate groups in a particular area. Similar to Lyon's (1994) repressing and protecting 'Janus-faces' of surveillance, here CCTV operates in a simultaneously fragmenting and consolidating capacity.

On a related theme, elsewhere in the city the process of acquiring CCTV for an area was seen by practitioners to have distinct benefits that were quite separate from its post-installation operations. Adding to the existing litany of its cited roles, one practitioner - responsible for coordinating crime policy across a large area in the south of Metropolitan City and, more 
importantly, compiling CCTV bids - felt that the 'process of getting CCTV' was 'as much the positive thing as the actual CCTV itself' (Interview 33a). Nevertheless, it was felt that engaging residents as part of the bidding process for CCTV would generate informal intra-community networks and, hence, enhance community cohesion, whilst also connecting community desires with the enabling policies of local authorities. Such perceived cohesive effects of community interaction also suggest connections with later Chicagoan ideas of 'community efficacy' (see Sampson et al., 1997). Hence, for practitioners, CCTV begins to provide a function through its very existence, whether as material installation or in a mooted form in more abstract decisionmaking forums. In this manner, practitioners consider that CCTV fulfils a purpose before it is even installed.

These symbolic features of CCTV raise a number of significant points of discussion. The first of these regards the potentially downgraded importance of CCTV effectiveness amongst other pressing obligations. Moreover, beyond sole issues of legitimacy, deeper, more ancillary 'presurveillant' functions for CCTV denote the crucial function of public camera surveillance before it is switched on, in some cases before implementation and, intermittently, (concerning the installation of imitation cameras in one Industrial Town estate) whether switched on or not. ${ }^{7}$ On one level, this supplies an interesting caveat to McCahill's (2002: 46) argument that 'on its own CCTV technology does nothing'. Whilst this is almost certainly true in erms of its manifest operation and accurately reflects a question mark over its deterrent capacities; for practitioners at least, CCTV installation fulfils a number of presurveillant functions. However, despite practitioner belief in the effectiveness of such additional applications, there is presently little research to justify these claims. Moreover, while a number of commentaries on CCTV make valuable points regarding its operational function, often contained is an implication that these same conceptual principles and processes inform its implementation. The evidence here, however, suggests that on their own, these perceived presurveillant benefits can be enough to stimulate CCTV expansion. ${ }^{8}$ Taking a cue from Norris and Armstrong's (1998: 8) argument that CCTV needs to be understood critically as 'a form of power with a number of dimensions', presurveillance represents an additional and substantial face of CCTV functionality.

Such latent utility may also set public CCTV schemes apart from other technological forms of surveillance and information gathering, such as biometric surveillance or 'smart' ID cards. In these latter modes, through their very existence the technology itself asserts a function by capturing data. With CCTV, such 'capture' is not necessarily assured. Thus, for CCTV, it is not necessarily the technology that does the work, but the contingent responses of surrounding actors. 9

\footnotetext{
7 Other pre surveillance functions can also be negative, as seen by the redoubled exclusionary impact of CCTV installation outlined below.

8 This is not to suggest that perceived operational functions are absent from decisions to implement CCTV. They clearly can be present. Considerations over presurveillant and operational functioning are, therefore, by no means mutually exclusive. Thus, the point here is that CCTV implementation is not all about its operational functions (crime control or otherwise). Before this stage, from its inception, CCTV is deemed to be serving a purpose and this alone can be enough to drive its implementation.

${ }^{9}$ Whilst arguing that human responses to surveillance installations are paramount may suggest an undercurrent of acceptance for the panoptic model, a number of crucial differences exist. Primarily, the
} 


\section{Demands for surveillance}

\section{Perceived public support}

Perhaps the key demand-orientated driver appears to be the srength of pro-surveillance discourse amongst the public. Across both partnerships practitioners commonly referred to the levels of public support for CCTV and the frequency with which it was requested. Although public support for CCTV is perhaps fairly unremarkable in itself, its significance lies in the way that policy structures convert demand into manifest strategies. 10 Once the decision to implement CCTV is taken, the next step towards installation involves securing funding. Current funding arrangements stipulate that this can only be gained following a formal consultation with the local community. This return to communities signifies a 'doubling-up' impact of residential support for CCTV. Thus, first, the demand for CCTV originates from the community; after, it is used to drive the policy-process along. This indicates the significant and instrumental role of public support in determining whether CCTV is installed or not.

Such levels of public support also reflect on a number of theoretical themes, specifically depictions of surveillance as a coercive tool of the malign state. Here, many of those requesting residential-space CCTV belong to those same disadvantaged groups who would be subject to such 'coercion'. In Metropolitan City, for example, large le vels of support for CCTV were evident in one of most disadvantaged estates in Britain. This suggests the need for such neoMarxist approaches to be reconsidered. One solution may be the incorporation of Gramsci's (1971) notion of hegemony to explain how local communities accept government definitions of CCTV. Indeed, there are clear similarities between such community views on the applicability of CCTV and those outlined by the government (see Home Office, 1994). Moreover, government recommendations to maximise the potential deterrence effects of surveillance cameras through constant reinforcement of positive CCTV messages, wherever possible (ibid.), may compound this process. However, the negotiations and conflicts amongst local practitioners over the application of CCTV (see below) supplies an interesting caveat to the issue of how such hegemony, if it exists, is negotiated.

responses to technology are not characterised in terms of discipline. The focus is less on those individuals actually under surveillance, and more on the actors responsible for, or those who may benefit from, CCTV installation. These include local politicians seeking credibility, partnerships gaining legitimacy, attempts to grant communities infrastructure and cohesion and residents requesting alleviation from fear. Sometimes the cameras do not necessarily need to exist where the idea of potential CCTV installation may be sufficient in achieving these goals. Foucauldian disciplinary normalisation is thus a separate issue and, given the reduced emphasis on effectiveness, possibly one of lesser importance.

10 Although a level of caution is required when considering claims of public support for CCTV. As Ditton (1998) argues, methodological flaws, such as the use of leading questions in quantitative questionnaires, can lead to extremely diverse results. Similar poor methodological practices were evident in one Industrial Town consultation where residents were sent a 'public consultation proforma' which asked the leading question of 'I would support the installation of two CCTV cameras: Yes or No'. Indeed, this is not really a question at all, but a statement of intent worded in such a way as to invite acceptance on the part of the respondent. 
However, because practitioners only seek consent for CCTV installations amongst certain wellplaced groups, wider hegemonic negotiation is neither secured nor necessary. Specifically, limitations on practitioners' time resources mean that they certain parts of the bidding process become abridged, by which the main casualty of this is adequate community consultation. As a result, the views of particular 'vocal groups', such as those who attend council consultation meetings, are amplified and attributed greater significance. As a corollary, the so-called 'hardto-reach' groups - populated by young people, particular ethnic minorities and gay and lesbian demographics - are most likely to become excluded from consultation exercises. Thus, the specific functioning of the policy context renders genuine democratic consultation less important than it initially appears. ${ }^{11}$ Moreover, his 'over-consultation' of empowered groups both supports arguments proposing that dominant groups in society are favoured in crime-control policy (inter alia, Boddy, 1992; Gilling, 1999) and ensures that those most likely to be the subject of surveillance-based social sorting (see inter alia Norris and Armstrong, 1999) are least likely to be involved in decisions over its implementation. This process of policy implementation therefore amplifies the exclusionary potential of CCTV.

\section{Police endorsements}

Another demand driver is the substantial police support for CCTV. Because partnership structures elevate the influence of police agency over others and owing to their unique role in disseminating crime-control 'expertise' (see Ericson and Haggerty, 1997), this support is significant and influential. More than being seen as a useful tool amongst many when tackling crime, CCTV is considered a premium strategy. In Metropolitan City, for example, the Police Community Safety Officer explained that when having to allocate resources to a particular strategy, CCTV is preferred over other measures including increased numbers of police officers. Such a preference is significant and raises an additional theoretical point concerning the disappearance of the individual through surveillance practices. Where Lyon (2001) notes the disappearance of the subject of surveillance through the abstraction of particular traits and measurable phenomena, here a desire for more remote (also considered as more efficient) forms of interaction with the subject of control is apparent through the substitution of police officers for distanciated surveillance.

So far, the above discussions suggest a process of CCTV implementation where practitioners' influence is compressed amid simultaneous demand pressures from below (involving calls for more cameras) and the supply forces (of resources, policy leads and 'solutions' to crime problems) from above. However, this paper argues that this does not lead to a simple translation into CCTV installation. Instead, such brces are filtered through, and consequently mediated within, crime reduction partnerships comprising of responsibilised actors, some of whom are ultimately the final arbiters over whether CCTV becomes installed or not. Moreover, this

\footnotetext{
11 As it stands, the government does not demand a detailed explanation of how consultations were carried out. For example, the Industrial Town partnership gained successful funding for a new CCTV installation with the following cursory reference to consultation in their bid document: ' $99 \%$ of respondents were in favour. A copy of the letter and some responses are enclosed'. Clearly, allowing (and rewarding) such practices represents an area where the Home Office could be stricter and thus help generate more robust local democratic structures.
} 
endorsement of CCTV is not necessarily shared by all practitioners and significant contestation within partnerships over the value CCTV interrupts the transmission of surveillance policy between its conception and its application. This paper now turns towards an analysis of the space in which such discord is articulated and negotiated.

\section{Negotiated Surveillance}

The above discussion has demonstrated how CCTV dissemination often does not occur as an objective solution to identified problems and is instead mediated by forces of demand and supply. Thus, combinations of fluid arrangements and extraneous factors have a greater impact on whether CCTV is installed than is recognised in many practical and theoretical accounts of surveillance. Rather than practitioners passively carrying out pre-ordained rationalist agendas or succumbing to fixations over technology, these contested sites are the forums through which CCTV policy becomes transmitted. Moreover, as the following discussion demonstrates, significant contestation over CCTV exists throughout both partnerships, which needs to reach some form of resolution - whether by consensus, negotiation or otherwise - for the cameras to be installed. In effect, this represents a significant interruption in the transmission of CCTV policies from proposal to practice. Here, it is also important to note some of the issues that prevent and forestall the implementation CCTV.

Analysis of the levels of practitioner's support for CCTV reveals a complex and sometimes conflicting set of issues. Generally speaking, most practitioners articulated some reservations over CCTV, an issue which challenges assumptions that practitioners view CCTV as a panacea (inter alia Davies, 1996b). This raises an additional set of questions concerning if and how these reservations become mobilised and articulated. Another question concerns whether, in spite of acknowledged drawbacks to camera surveillance, practitioners proceed with the implementation of CCTV as either a kind of 'bad faith', or succumb to other driving pressures. Both of these discussions are developed below. First, however, is a brief examination of the form in which these reservations take.

One finding of note here is how objections to CCTV based on civil liberties and intrusion, whilst present, were not significantly replayed in these partnerships. Instead, contestations over CCTV were overwhelmingly centred on issues of effectiveness. ${ }^{12}$ However, practitioners did not just disagree over the effectiveness of CCTV, but also why it is ineffective.

\footnotetext{
12 Nevertheless, ambiguity surrounding human rights legislation did forestall one potential CCTV scheme aimed at targeting burglary suspects in Metropolitan City. Instead, funds were diverted towards strategies aimed at 'designing out' burglary. This tabled CCTV strategy was substituted, not over concerns for preserving the rights of the surveilled, but to ensure the police were protected against litigation. In addition to underlining the position of practitioners as final arbiters over the installation of this surveillance system, this policy choice suggests a preferred deployment of cameras for broader, indiscriminate surveillance practices rather than more subject-orientated monitoring. However, when talking about surveillance generally, it is in the latter application where many commentators feel the most effective function of CCTV lies (Innes, 2003; Lyon, 2004b).
} 
Of these issues, displacement was commonly cited as a limitation of CCTV. Within this category, practitioners were only concerned with the spatial displacement of crime, rather than other forms, such as the tactical displacement of crime type (see inter alia Felson and Clarke, 1998). Although spatial displacement was a concern for many, the infusion of managerialist procedures into local crime control decision-making meant this was not a concern for all. Indeed, abstract borders imposed by localised managerial performance indicators left one senior practitioner (responsible for crime reduction in a southern district of Metropolitan City) happy for CCTV to displace crime, provided that it was away from his area of responsibility. Clearly, such attitudes from those with an instrumental role in installing CCTV generate a range of important issues. These include potential inter-agency conflict over the installation of such schemes in adjacent areas; the possibility of a downgraded emphasis on reducing crime and social harm across large urban geographies; and the potential for discord between local and regional goals. Either way, not only do such attitudes counter practitioners' claims of 'joined-up thinking', but also reveal some rather spurious reasons for wishing to install CCTV.

Other debates over effectiveness concerned image reproduction and the 'perfection' of surveillance. Metropolitan City was one of the first cities in the UK to install a comprehensive CCTV system (CCTV was first installed in Metropolitan City in 1988, with a major upgrade during 1991). As a result, much of the hardware has become outdated and superseded by more advanced technology. This was not lost on practitioners, among whom recognition of technological improvements in camera surveillance has stimulated renewed aspirations for updated systems and an awareness of the limitations of existing facilities. ${ }^{13}$ Such drives towards continual improvement of surveillance provisions partially reflect on Bogard's (1996) Baudrillardian descriptions of perfecting surveillance. Yet in Metropolitan City this occurs in a more grounded sense regarding the instruments of image capture rather than the perfecting of simulation processes. This goal of updating surveillance systems in response to inadequately reproduced images raises an interesting point concerning shifting perceptions of technological capabilities. At the time of installation, could these images, now considered distorted, have been seen with clarity? Certainly, the quality was deemed adequate for the strategy to be rolled out across large parts of the city. Part of the explanation may lie in the perceived innovative nature of the approach during an era of 'nothing works' and ever-spiralling crime rates (coupled with a 'common sense' logic of CCTV effectiveness that narrows objections). These factors suggest the possibility of technological and surveillance discourses specific to the period of initial implementation which, in light of the current myriad supply and demand influences impacting on CCTV implementation, may no longer fully apply. Nevertheless, the increasing growth of surveillance, despite its untested nature, is a familiar story and one currently replayed in Metropolitan City.

After displacement issues, the next frequently cited drawback of CCTV concerned fallibilities in the 'response network' surrounding surveillance cameras. This network is defined here as the process that intercedes between an event occurring before a camera and subsequent action,

\footnotetext{
13 Rather than pressure from the security industry for increased and improved surveillance apparatus (as argued by Graham, 1998), this data identifies demand as generated within the partnership in recognition of the limitations of the older earlier systems.
} 
whether this represents deployment of enforcement agents or later evidential use of images. Hence, the response network incorporates fallibilities of operators, agencies charged with responding to incidents detected on CCTV and breached integrity of information garnered from CCTV.

One such issue related to concern amongst senior practitioners that incidents spotted on camera are effectively followed up by enforcement agencies. Two key themes arise from this concern. Firstly, CCTV does not necessarily ensure an active response from associated enforcement agencies (as Norris and Armstrong (1999) and McCahill (2002) demonstrate). ${ }^{14}$ This supplies a caveat to the strength of CCTV as deterrence. Like its classicist underpinnings, deterrent effects recede without swift and consistent reinforcement of punitive capabilities. This may add some explanation to Tilley's (1993) identification of the limited longevity of CCTV schemes. These issues suggest that any deterrent effect of CCTV may be enhanced through its location within a suitably responsive network.

Senior members of the Metropolitan City partnership also adjudged technological efficacy as contingent on human interventions, particularly with reference to the problems of identifying individuals from live and recorded footage. Such difficulties in capturing an image during or after its occurrence suggest that post-surveillance interpretations and modulations - of the kinds outlined by Deleuze (1995) and adherents such as Haggerty and Ericson (2000) - can become difficult to achieve. Although previously identified moves to update CCTV systems in Metropolitan City may enable greater facilitation of this task, more intractable human frailties still interrupt the conveyance of the surveilled image.

Aside from these fallibilities concerning the human linkages in punitive and surveillance networks, one of the most striking research findings concerns the unawareness of the police of a public CCTV scheme in an inner-city area of Metropolitan City:

There was CCTV set up in one of the estates. I didn't even know it was there for nearly five years. The people who are paid to monitor it, it was in [location]... The quality of the cameras was very poor; the product from the cameras was very poor so it just fell into disuse

(Interview 35).

This demonstrates the extent of fragmented network arrangements surrounding surveillance. Hence, forces other than those seen to pull 'surveillant assemblages' together (Haggerty and Ericson, 2000) are in evidence. Instead, the abandonment of this system suggests a form of atrophy within surveillance networks. In addition, lack of awareness over the existence of public CCTV systems may undermine assurances that civil liberties concerns are being observed.

\section{Interpreting discord overCCTV}

\footnotetext{
14 Indeed, as Norris and Armstrong (1999) show, CCTV surveillance rarely catalyses deployment, sometimes even when actual crimes are being observed.
} 
Amongst practitioners, then, discourses of CCTV appear contested. Despite reservations, however, CCTV installations were not necessarily rejected outright and continued to be implemented. In a number of cases, individuals either doubted or were indifferent to the capabilities of CCTV, yet still undertook action that was instrumental in securing its installation. This is illustrated in two examples, one from each partnership.

In Industrial Town, a central figure in the process of requesting CCTV for a residential area to tackle crime and disorder earlier asserted that the cameras do not stop 'real crime', 'won't stop the basic problem', that 'there's a real question mark over them' and, in reference to burglary, 'I don't think CCTV would make any difference whatsoever' (Interview 3). In Metropolitan Cty, CCTV installation was also pursued despite uncertainty over its potential effectiveness. When asked about the effectiveness of CCTV, an Area Co-ordinator for a southern area of city, heavily involved in mobilising local support and compiling - by her own admission, elaborate bids for Home Office CCTV funding in the area, said 'it's not something I know a great deal about ... There's been no proper research done on the findings really, believe it or not (Interview 33a). Thus effective CCTV applications are not always considered a prerequisite for its installation.

Both of these examples demonstrate attempts to implement CCTV by practitioners harbouring either scepticism or indifference over its likely effectiveness. On this evidence there may be an argument that practitioners are acting in 'bad faith' 15 in their attempts to install CCTV. Certainly, the recurring theme of scant regard for evaluation, and hence compromised rationality, is present. However, one can argue that particular reasons can help understand why effectiveness appears to be downgraded amongst other demands.

What emerges most strongly in this body of data is how situational and contextual factors exert pressures which skew decision-making towards CCTV deployment and serve to 'paper over' deeper conflicts. Such pressures specifically concern the way in which policy is made. This may include a number of issues including differential partnership stratification; pressure to cultivate legitimacy; available expertise or capacity to implement alternatives; the existence of earmarked funding; pressure from the sections of communities consulted; and agents' acquiescence to existing partnership consensus over key policy orientations. All of these may combine to stimulate the implementation of CCTV. Hence policy arrangements may result in objections to CCTV being overcome in a trade-off of individual agency in order to achieve wider organisational and strategic goals. These goals may also stretch beyond controlling crime and incorporate the aims of enhancing credibility and securing partnership stability, and thus also underlines the importance of the 'presurveillant' functions of CCTV highlighted earlier.

Additionally, resolute public demands harnessed by the policy process (and political agents) can pressure practitioners into action; an issue that operates in isolation from debates over effectiveness. This was clearly demonstrated in the above example of the practitioner's indifference to the capabilities of CCTV whilst in the process of compiling a bid for Home Office funding (Interview 33a). Thus, a clear distinction over the enthusiasm for CCTV is

15 See Cohen (2001) for a comprehensive discussion on the concept of action in 'bad faith'. 
apparent between practitioners and amongst those sections of the community where consent was sought. Moreover, this demonstrates how obligations imposed by the policy context may affect CCTV dissemination, where public wishes for technological surveillance, whilst not necessarily shared by practitioners, become mobilised and transmitted through the contextual arrangements in which they are filtered. Hence, the process of implementation itself becomes instrumental to the dissemination of CCTV.

In the broader setting, other forms of conflict resolution can also influence decisions over CCTV deployment. For example, conflicts may be resolved where powerful members reassert their authority, thus fortifying the initial conditions that emphasise enforcement and surveillance 'solutions' to problems of crime and disorder. One such example is the statement by the senior police representative - a central figure in the Metropolitan City partnership - that there was 'no point sitting down with individuals' he had 'no control over' (Interview 35). Thus, partnership negotiations over CCTV can generate powerful coalitions of consensus to drive the process along in particular directions, therefore conflicting with public claims of democratised and inclusive approaches towards strategic development. Hence, whilst continuing CCTV expansion may give an impression of unequivocal practitioner consensus over its benefits, it masks the significant negotiations and tensions that simmer beneath. Ultimately, this discussion demonstrates how public CCTV dissemination can be a product of conflict, not of consensus.

\section{Discord and corporate interest-based surveillance}

The research also identified significant disagreements within commercial spheres over CCTV installation. Whilst many political-economic accounts offer valuable observations regarding corporate agendas and public surveillance, the data suggests an additional dimension to these relations. This particularly concerns a disharmony between these actors which suggests that commercial values are not necessarily transmitted into CCTV implementation.

In the first instance, commercial decisions over surveillance may also become subject to corporate logics of profit and loss. This issue was clearly articulated by a representative of Metropolitan City's chamber of commerce: 'as a Chamber, we feel there are more effective ways of dealing with crime because CCTV cameras are very expensive' (Interview 16). ${ }^{16}$ Closer examination of this theme suggests that, despite initial support for the cameras, enthusiasm significantly declined once businesses were required to pay for its management. Here, the applications of commercial values can be seen to work against installations. One way this happens concerns the tension between raising money for capital and then ensuring that the running costs can be met (under current Home Office funding arrangements, the government requires the latter to be provid ed locally). Both partnerships experienced problems where capital costs were secured from the government but local traders, despite earlier assurances,

\footnotetext{
16 When pressed on what these 'better ways of dealing with a problem' were, this participant cited low-tech surveillance solutions relying on the observations of human agents, such as community 'ring-round' schemes.
} 
were unwilling to contribute towards the running costs, causing the government to withdraw its initial funding. ${ }^{17}$

This occurred in both partnerships during the period of research. In Industrial Town, for example, one successful bid of $£ 187,000$ for significant CCTV expansion (boosting the number of the town's cameras by a fifth) collapsed at the implementation stage for this reason. Local businesses reneged on their written commitments (included in the bid document) to contribute $£ 1,500$ each per annum towards the running costs of the scheme. Similarly, one local practitioner describes the shifting perspectives of local traders in one area of Metropolitan City after initially asking for CCTV to be installed:

traders were loathe to take responsibility for paying revenue costs. It worked out at about ten pounds per week per trader. And the traders said 'What's the point? The cameras will be useful in picking up fighting in the streets at night but we are already shut by then and, to be honest, having shutters on our shop is a better deterrent for us than cameras on the streets'. So there have been a couple of failed attempts in Metropolitan City to set up CCTV.

(Interview 22) 18

Such variations in support for CCTV, conditional on external investment, indicate that desires for surveillance often only run as deep as financial prudence allows. Moreover, were state funding extended to cover operational management of the cameras, we would undoubtedly see even more CCTV cameras on the streets of England and Wales.

Considering the final implementation of CCTV, clearly much depends on both the political will and available resources within local authorities at that time and in that location. Earlier instances of such corporate equivocation, for example, had led the Metropolitan City Council to shoulder the deficit of managerial costs to rescue the installation which, as a corollary, amplified the reticence of other businesses to support CCTV management throughout the city. Whilst this data confirms Fyfe and Bannister's (1996) contention that public and private partnerships are fraught with potential tensions, their explanation, that this is because local councils are reluctant to commit public funds to projects serving commercial interests, can be reconsidered. Instead of corporate interests lobbying reluctant councils for CCTV implementation, contestations over CCTV were played out between and within commercial and council bodies. ${ }^{19}$ Moreover, because the council committed public funds to schemes once businesses have been unwilling to pay and because this took place in a largely residential area where (sections of) the public were

\footnotetext{
17 The collapse of these bids may also undermine trust in the partnership, once CCTV has been promised. Practitioners also acknowledge the undermining of such trust as a major cause of fear of crime. Thus potentially contributing to the problem that CCTV installation was originally intended to tackle.

18 Interview 22 was conducted with a representative of the probation service who had been seconded to work at a senior level within the Metropolitan City partnership.

19 This is not to suggest that CCTV implementation involves constant struggles between commercial and council entities; merely that contestation can and does exist.
} 
mobilised in their demands for CCTV, the differential surveillance contexts of residential and commercial spaces are underlined.

However, commercial support for CCTV may also be discordant within itself depending on the configuration of businesses in urban spaces. For example, a different estate in Metropolitan City experienced significant conflict arose owing to smaller traders' anger that larger businesses (such as banks and multinationals) were not investing significantly more towards the management costs of CCTV. Hence, rather than the transmission of a homogenous set of corporate values into manifest CCTV installation, significant disagreement is in evidence. It may also be possible that such conflict and exacerbated feelings of injustice could reduce the likelihood of CCTV installation.

Overall, such shifting and discordant relations between local authorities and commercial interests, alongside the evidence of intra-commercial rivalry, indicate a greater complexity of corporate involvement and a more splintered set of values than many political-economic accounts suggest (inter alia Williams et al., 2000). This locational specificity of CCTV implementation also points to the difficulties of presenting political and economic influences as necessarily coterminous when conceptualising CCTV dissemination across whole urban geographies.

\section{Conclusions}

Overall, this paper has demonstrated how a number of contextual and circumstantial forces such as supply, demand and negotiations within stratified partnerships - intersect and are harnessed by specific policy-making arrangements to generate stimulus for CCTV expansion. Together, these factors constitute the process that motivates the implementation of CCTV into practice. In doing so, the messy and interrupted transmission of surveillance policy from conception to material implementation reveals myriad influences of agency and structure that shape CCTV diffusion. Regarding influences of agency, responsibilised practitioners assert a decisive influence upon both the manifestation and spatial positioning of camera installations. In such respects, these agents are the final arbiters of CCTV diffusion.

However, such assertions of agency do not function in an unfettered (and constructivist) manner. Rather, an identifiable structural, conceptual and material environment enables and constrains the way in which such actions operate. Within these environments, practitioners responsible for implementing CCTV need to mediate the demands of an empowered section of the public; commit to servicing local democracy; generate their own legitimacy; engage in intra-partnership disputes and struggles for ascendancy; and respond to a policy context orientated around increasing surveillance techniques. Limited managerial resources and opportunities for reflexivity within stratified partnerships also cultivate heavy emphasis on responsive and enforcementbased approaches. Coupled with this, for practitioners, CCTV also fulfils a number of crucial 'presurveillant' functions. Taken cumulatively, the policy end of CCTV implementation reflects the process means that bring it into existence. 
This identification of such crucial assertions of agency and structure upon the development and transmission of CCTV policy also creates space for the application of different theoretical positions to understand its deployment. In particular, further research could draw on integrative sociological theories in an attempt to gain a more detailed sense of how agency and structure both interrelate and mutually construct one another in relation to CCTV dissemination. Although currently an underdeveloped area in the field of criminology (with a few exceptions, inter alia Bottoms and Wiles, 1992; also see Vaughan, 2001), future analysis could draw on integrative frameworks such as those developed in Giddens' (1984) 'structuration theory' or Bourdieu's (1994) conceptualisation of 'habitus' and 'field'.

Overall, the pre-operational dissemination of CCTV is, therefore, neither necessarily utopian nor dystopian in nature, but rather hostage to these impositions of agency and structure. Whilst some theoretical commentaries have acknowledged deeper contestations and forces surrounding CCTV expansion, this paper has both drawn attention and contributed detail to the nature of these interactions and how they affect the formulation of CCTV strategies in its material and conceptual settings. In the process of such analysis, the transmission of surveillance has been characterised as a messy and irregular process subject to myriad influences, thus augmenting citations of coherent or singular organising principles explaining its expansion. Because CCTV fulfils multiple roles, it cannot be coalesced into any single agenda; materialistic, political or otherwise. Taken cumulatively, the processes behind the expansion of camera surveillance are diffused through complex interactions of structure and agency which are, in turn, filtered through contingent and shifting policy arrangements.

\section{References and Bibliography}

Bannister, J., Fyfe, N.R. and Kearns, A. (1998) 'Closed Circuit Television and the City', in Norris, C., Moran, J. and Armstrong, G. (eds.) (1998) Surveillance, Closed Circuit Television and Social Control, Aldershot: Ashgate. pp. 21-41

Beck, A. and Willis, A. (1995) Crime and Security: managing the risk to safe shopping, Leicester: Perpetuity Press

Boddy, T (1992) 'Underground and Overhead: Building the Analogous City', in M. Sorkin (ed.) Variations on a Theme Park: The New American City and the End of Public Space, New York: Hill and Wang. pp. $123-54$

Bogard, W. (1996) The Simulation of Surveillance: Hypercontrol in telematic societies, Cambridge: Cambridge University Press

Bottoms, A., and Wiles, P., (1992) 'Explanations of Crime and Place', in D. J. Evans, N., Fyfe, and D. Herbert (eds.) Crime, Policing and Place: Essays in Environmental Criminology, London: Routledge

Bourdieu, P. (1990) The Logic of Practice, Cambridge: Polity

Brenner, N., and Theodore, N. (eds.) (2002) Spaces of Neoliberalism: urban restructuring in North America and Western Europe, Oxford: Blackwell

Cohen, S. (2001) States of Denial, knowing about atrocities and suffering, Oxford: Polity 
Coleman, R. (2004) 'Reclaiming the Streets: Closed Circuit Television, Neoliberalism and the Mystification of Social Divisions', in Surveillance and Society, 2(2/3) pp. 293-309

Coleman, R., and Sim, J. (1998) 'From the Dockyards to the Disney Store: Surveillance, Risk and Security in Liverpool City Centre', in International Review of Law, Computers and Technology, 12(1) pp. 27-45

Coleman, R. and Sim, J. (2000) 'You'll Never Walk Alone: CCTV surveillance, order and neo-liberal rule in Liverpool city centre', British Journal of Sociology, 51(4) pp. 623-639

Crawford, A. (1998) Crime Prevention and Community Safety: Politics, Policies and Practices, London: Longman

Crowther, C (2000) Policing Urban Poverty, Basingstoke: Macmillan

Davies, S. (1996a) Big Brother, London: Pan

Davies, S. (1996b) 'The Case Against: CCTV should not be introduced', International Journal of Risk, Security and Crime Prevention, 1(4) pp. 327-331

Davis, M. (1998) Ecology of Fear: Los Angeles and the Imagination of Disaster, New York: Metropolitan Books

Deleuze, G. (1995) 'Postscript on Control Societies', in Negotiations 1972-1990, New York: Columbia University Press pp. 177-183

Ericson, R.V. and Haggerty, K.D. (1997) Policing the Risk Society, Oxford: Clarendon Press

Foucault, M. (1977) Discipline and Punish: The Birth of the Prison, London: Penguin

Fussey, P. (2004) 'New Labour and New Surveillance: Theoretical and Political Ramifications of CCTV Implementation in the UK', Surveillance and Society 2(2/3) pp. 251-269

Fussey, P. (2005) Installing CCTV: A Study of the Networks of Surveillance Policy, unpublished PhD thesis, Brunel University

Fyfe, N. R. (2004) 'Zero Tolerance, Maximum Surveillance? Deviance, Difference and Crime Control in the Late-Modern City', in L. Lees (ed.) The Emancipatory City? Paradoxes and Possibilities, London: Sage, pp. 40-56

Fyfe, N. R., and Bannister, J. (1996) 'City Watching: Closed Circuit Television in Public Spaces', in Area 28(1) pp. 37-46

Garland, D. (1996) 'The Limits of the Sovereign State: strategies of crime control in contemporary society', British Journal of Criminology, 36 (4) pp. 445-471

Garland, D. (2001) The Culture of Control: crime and social order in contemporary society, Oxford: Oxford University Press

Giddens, A. (1984) The Constitution of Society, Cambridge: Polity

Gilling, D. (1999) 'Community Safety: a critique', from the British Criminology Conferences: Selected Proceedings, Volume 2

Graham, S. (1998) 'Towards a Fifth Utility? On the extension and normalisation of public CCTV', in C. Norris, J. Moran, G. Armstrong (eds.) Surveillance, Closed Circuit Television and Social Control, Aldershot: Ashgate 
Graham, S. and Marvin, S. (1996) Telecommunications and the City: Electronic Spaces, Urban Places, London: Routledge

Graham, S., Brooks, J. and Heery, D. (1996) 'Towns on the Television: Closed circuit TV in British Towns and Cities', Local Government Studies, 22(3) pp. 3-27

Gramsci, A. (1971) Selections from the Prison Notebooks, London: Lawrence and Wishart

Haggerty, K. and Ericson, R. (2000) 'The Surveillant Assemblage', in British Journal of Sociology, 51(4) pp. 605-622

Heritage, J. (1984) Garfinkel and Ethnomethodology, Cambridge: Polity

Hier, S. P. (2003) 'Probing the Surveillant Assemblage: on the dialectics of surveillance practices as processes of social control', Surveillance and Society, 1(3) pp. 399-411

Home Office (1994) CCTV: Looking Out for You, London: Home Office

Home Office (2000a) The Crime Reduction Programme: Second Round of the CCTV Initiative, http://www.crimereduction.gov.uk/cctvmin.htm.

Home Office (2000b) CCTV Initiative Application Prospectus, guidance and form for the application of Home Office funding for CCTV schemes, http://www.crimereduction.gov.uk/cctvpros.htm

Home Office (2001) CCTV Initiative: Application Prospectus, on the Government's Crime Reduction website: http://www.crimereduction.gov.uk/cctvpros.htm

Home Office (2004) Crime Reduction Toolkits, available from http://www.crimereduction.gov.uk/toolkits/index.htm

The Independent (2004) 'Big Brother Britain, 2004', Monday $12^{\text {th }}$ January, page 1

Jones, R. (2000) “Digital Rule': Punis hment, Control and Technology’, Punishment and Society, 2(1) pp. 5-21

Lyon, D. (1994) The Electronic Eye: the rise of the surveillance society, Oxford: Polity

Lyon, D. (2001) Surveillance Society: Monitoring Everyday Life, Buckingham: Open University Press

Lyon, D (2002) 'Editorial. Surveillance Studies: Understanding visibility, mobility and the phenetic fix', Surveillance and Society, 1(1) pp. 1-7

May, T. (1997) Social Research: Issues, Methods and Process, Buckingham: Open University Press

McCahill, M. (2002) The Surveillance Web: The rise of visual surveillance in an English city, Cullompton: Willan

McCahill, M. \& Norris, C (2002) 'Literature Review, Working Paper No.2', from the Urban Eye: On the Threshold to Urban Panopticon? Analysing the Employment of CCTV in European Cities and Assessing its Social and Political Impacts European Commission project. Available from http://www.urbaneye.net/results/ue wp2.pdf

NACRO (2002) To CCTV or not to CCTV: a review of current research into the effectiveness of CCTV systems in reducing crime, Community Safety Practice Briefing, May.

Newburn, T., and Hayman, S. (2001) Policing, Surveillance and Social Control: CCTV and Police Monitoring of Suspects, Cullompton: Willan 
Norris, C., and Armstrong, G. (1999) The Maximum Surveillance Society, Oxford: Berg

Norris, C., and McCahill, M. (2006) ‘CCTV: Beyond Penal Modernism?’ British Journal of Criminology 46(1) pp. $97-118$

Pawson, R. and Tilley, N (1994) 'What works in Evaluation Research?’ British Journal of Criminology, 34(3) pp. $291-306$

Sampson, A., Stubbs, P., Smith, D., Pearson, G. and Blagg, H. (1988) 'Crime Localities and the Multi-agency Approach', British Journal of Criminology, 28(4) pp. 478-493

Seabrook, T., and Wattis, L. (2001) 'The Techno-flâneur: Tele-erotic re-presentation of women's life spaces', in L. Keeble and B. Loader (eds.) Community Informatics: Shaping Computer-Mediated Social Relations, London: Routledge

Sennett, R. (1990) The Conscience of the Eye: The Design and Social Life of Cities, New York: W.W. Norton

Short, E. and Ditton, J. (1995) 'Does CCTV Affect Crime?', CCTV Today, 2(2) pp. 10-12

Soja, E. (1989) Post-modern Geographies: The Reassertion of Space in Critical Social Theory, London: Verso

Sutton, A. and Wilson, D. (2004) 'Open-Street CCTV in Australia: Politics \& Expansion', Surveillance and Society, 2(2/3) pp. 310-322

Tilley, N. (1993) Understanding Car Parks, Crime and CCTV: Evaluating Lessons From Safer Cities, Home Office Police Research Group Crime Prevention Unit Series Paper no.42

Tilley, N. (1998) 'Evaluating the Effectiveness of CCTV Schemes', in C. Norris, J. Moran and G. Armstrong (eds.) (1998) Surveillance, Closed Circuit Television and Social Control, Aldershot: Ashgate, pp. $139-175$

Toon, I. (2000) 'Finding a Place in the Street: CCTV surveillance and young people's use of public space', in D. Bell and A. Haddour (eds.) City Visions, Harlow: Longman, pp. 141-165

Vaughan, B. (2001) 'Handle With Care: On the use of structuration theory in criminology', British Journal of Criminology, 41(1) pp. 185-200

Webster, C.W.R. (2004) 'The Evolving Diffusion, Regulation and Governance of Closed Circuit Television in the UK', Surveillance and Society, 2(2/3) pp. 230-250

Welsh, B. C. and Farrington, D. P. (2002) Crime prevention effects of closed circuit television: a systematic review, Home Office Research Study 252, London: Home Office http://www.homeoffice.gov.uk/rds/pdfs2/hors252.pdf

Williams, K., and Johnstone, C. (2000) 'The Politics of the Selective Gaze: Closed Circuit Television and the policing of public space', Crime, Law and Social Change, 34(2) pp. 183-210

Williams, K., Johnstone, C., and Goodwin, M. (2000) 'CCTV Surveillance in Urban Britain: beyond the rhetoric of crime prevention', in J.R. Gold, and G. Revill (eds.) Landscapes of Defence, London: Prentice Hall, pp. 168-187 